\title{
Regulations to Promote Healthy Sleep Practices in Child Care
}

AUTHORS: Sara E. Benjamin Neelon, PhD, MPH, RD, a,b Kiyah Duffey, PhD, c,d and Meghan M. Slining, PhD, MPHc,e

aDepartment of Community and Family Medicine, Duke University Medical Center, Durham, North Carolina; 'buke Global Health Institute, Durham, North Carolina; ' Department of Nutrition, Gillings School of Global Public Health, University of North Carolina at Chapel Hill, Chapel Hill, North Carolina; 'Department of Human Nutrition, Foods, and Exercise, Virginia Tech, Blacksburg, Virginia; and ${ }^{e}$ Department of Health Sciences, Furman University, Greenville, South Carolina

\section{KEY WORDS}

child care, obesity, policy, regulations, sleep

\section{ABBREVIATIONS}

IOM-Institute of Medicine

SIDS—Sudden Infant Death Syndrome

Dr Benjamin Neelon conceived of and designed the study, conducted the regulations review, and drafted the initial manuscript; Drs Duffey and Slining conducted the regulations review and reviewed and edited the manuscript; and all authors approved the final manuscript as submitted.

www.pediatrics.org/cgi/doi/10.1542/peds.2014-0578

doi:10.1542/peds.2014-0578

Accepted for publication Sep 10, 2014

Address correspondence to Sara E. Benjamin Neelon, PhD, MPH, RD, Associate Professor, Department of Community and Family Medicine, Duke University Medical Center and Duke Global Health Institute, 2200 W Main St, DUMC 104006, Durham, NC 27705. E-mail: sara.benjamin@duke.edu

PEDIATRICS (ISSN Numbers: Print, 0031-4005; Online, 1098-4275). Copyright (C) 2014 by the American Academy of Pediatrics FINANCIAL DISCLOSURE: The authors have indicated they have no financial relationships relevant to this article to disclose.

FUNDING: This study was supported in part by a National Institutes of Health grant R21HD070822. Additionally, the work was undertaken by the Centre for Diet and Activity Research (CEDAR), a UKCRC Public Health Research Centre of Excellence. Funding from the British Heart Foundation, Cancer Research UK, Economic and Social Research Council, Medical Research Council, the National Institute for Health Research, and the Wellcome Trust, under the auspices of the UK Clinical Research Collaboration, is gratefully acknowledged. Funded by the National Institutes of Health (NIH).

POTENTIAL CONFLICT OF INTEREST: The authors have indicated they have no potential conflicts of interest to disclose.
WHAT'S KNOWN ON THIS SUBJECT: Previous studies have examined state regulations for child care facilities and found substantial variation among states. None of these studies examined regulations related to healthy sleep practices, which is an important and often overlooked intervention target for obesity prevention.

WHAT THIS STUDY ADDS: We reviewed state regulations related to healthy sleep in child care and compared them to recent national recommendations put forth by the Institute of Medicine. We found that many states lacked regulations, highlighting an important and timely opportunity for improvement.

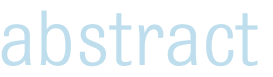

OBJECTIVES: The purpose of this study was to assess state licensing and administrative regulations promoting healthy sleep practices in child care and to compare these regulations to national recommendations.

METHODS: We reviewed regulations related to healthy sleep practices for all states and territories for both child care centers (centers) and family child care homes (homes). We compared regulations with Institute of Medicine recommendations to promote sleep in child care, including (1) create environments that ensure restful sleep; (2) encourage sleeppromoting behaviors and practices; (3) encourage practices that promote child self-regulation of sleep; and (4) seek consultation yearly from a sleep expert. We used Cochran-Mantel-Haenszel trend tests to assess associations between geographic region and number of regulations consistent with the recommendations.

RESULTS: The mean number of regulations for states was 0.9 for centers and 0.8 for homes out of a possible 4.0. For centers, no state had regulations for all 4 recommendations; 11 states had regulations for 2 of the 4 recommendations. For homes, 9 states had regulations for 2 of the recommendations. States in the Northeast had the greatest mean number of regulations for centers (1.2) and homes (1.1), and states in the South had the fewest ( 0.7 and 0.7 , respectively); these geographic differences were significant for centers $(P=.03)$ but not homes $(P=.14)$.

CONCLUSIONS: More states in the Northeast had regulations consistent with the Institute of Medicine sleep recommendations, but overall few states had regulations consistent with the recommendations. Pediatrics 2014;134:1167-1174 
Insufficient sleep is associated with a number of adverse health outcomes in childhood, including impaired cognition, diminished impulse control, and behavioral problems. ${ }^{1-3}$ Short sleep duration has also been associated with obesity in childhood in both cross-sectional and Iongitudinal studies. ${ }^{4-6}$ The mechanisms linking insufficient sleep to obesity are, in part, related to the hormonal regulation of hunger and satiety. Experimental studies in adults have shown that sleep restriction resulted in reduced levels of leptin, a hormone that suppresses appetite, and increased levels of ghrelin, a hormone that stimulates appetite. ${ }^{7,8}$ Inadequate sleep may also interfere with metabolic processes related to glucose metabolism,, 10 which can influence the development of obesity. Insufficient sleep, even in childhood, may contribute to poor dietary choices, leading to the consumption of low nutrient, high energy density foods. ${ }^{11,12}$ Short sleep duration may also impact energy expenditure, if those who are tired are less physically active and engage in more sedentary behaviors. ${ }^{13-16}$

A number of studies have examined sleep in early childhood, a time when sleep patterns change often and poor sleep habits may develop.,17-23 Taveras and colleges reported a twofold higher prevalence of obesity among infants and toddlers who slept less than 12 hours per day, compared with those who slept more, and observed a distinct dose-response relationship between sleep duration and obesity. ${ }^{19}$ Bell et al found that inadequate nighttime sleep, defined by age-specific sleep duration below the 25th percentile, was associated with subsequent obesity in children younger than 4 years of age..$^{20}$ A study in the United Kingdom found that inadequate sleep duration $<10.5$ hours per day at age 3 years was associated with obesity at age 7 years. ${ }^{18}$ Furthermore, results from the Toyama Birth Cohort Study suggest that 3-year-old children who slept $<9$ hours per day were more likely to be obese than children who slept $\leq 11$ hours. ${ }^{17}$
A number of studies have also examined environmental and behavioral factors related to sleep, including television and screen time viewing, the presence of a television in the bedroom, noise and light disturbances, urban living, inconsistent sleep schedules, and poor or irregular sleep routines, and found relationships with excessive weight gain and obesity. ${ }^{24-29}$ Television and screen time viewing and the presence of a television in the bedroom, in particular, negatively influenced sleep duration in young children. ${ }^{24-27}$ Wilson et al examined sleep environments of preschool-aged children and found that environments that were too hot, cold, bright, or loud decreased nighttime sleep duration by 27 minutes. ${ }^{29}$ Thus, efforts to improve the environments where children sleep are warranted, and may include both the family home and child care settings. Because nearly 13 million young children in the United States spend time in out-of-home child care, ${ }^{30,31}$ this setting has emerged as an important target for obesity prevention. ${ }^{32,33}$

In 2011, the Institute of Medicine (IOM) released policy-based recommendations to help prevent obesity in young children, including specific recommendations related to sleep duration and sleep hygiene. ${ }^{34}$ The IOM report included recommendations for state licensing and administrative agencies to regulate healthy sleep practices in child care. Little is known about the extent to which the new IOM recommendations are being implemented by states. The purpose of this study was to review state regulations related to sleep behavior in child care, assess consistency with the IOM recommendations, and explore geographic differences in states meeting the IOM recommendations.

\section{METHODS}

\section{Overview}

For this cross-sectional study, we compared existing state licensing and ad- ministrative regulations to recent national recommendations to promote healthy sleep practices in child care, excluding sleep regulations related to the prevention of Sudden Infant Death Syndrome (SIDS). Because this study was a policy review and did not involve human subjects, ethical approval was not required by Duke University Medical Center.

\section{Sleep Recommendations}

We identified 1 overarching recommendation from the IOM policy report that targeted healthy sleep practices related to obesity prevention for children in child care. The recommendation stated that "child care regulatory agencies should require child care providers to adopt practices that promote age-appropriate sleep durations among young children." ${ }^{34}$ The IOM noted 4 potential actions ("recommendations") to achieve this goal, including (1) create environments that ensure restful sleep, such as no screen media in rooms where children sleep and low noise and light levels during napping; (2) encourage sleep-promoting behaviors and practices, such as calming naptime routines and avoiding stimulating or stressing children just before naptime; (3) encourage practices that promote child self-regulation of sleep, including putting infants to sleep drowsy but awake and helping older children identify feelings of sleepiness; and (4) seek consultation yearly from an expert on healthy sleep durations and practices. ${ }^{34}$ These overarching recommendations are not age-specific but encourage healthy sleep practices in all children in child care.

\section{State Regulations Review}

We reviewed each state's licensing and administrative regulations for child care facilities between August and December of 2013, focusing on regulations consistent with the IOM recommendations. A trained reviewer (Dr Neelon) searched 2 sources for regulations using primary legal research methods: a publically 
available Web site maintained by the National Resource Center for Health and Safety in Child Care in partnership with the American Academy of Pediatrics, ${ }^{35}$ and the commercial legal research database WestlawNext. Each state's regulations were coded by the reviewer using a combination of Boolean keyword searches and review of the full text. ${ }^{36}$ Two additional reviewers (Drs Duffey and Slining) conducted separate reviews using the National Resource Center Web site; their reviews were collapsed and compared with the first review as a measure of quality control. Agreement between the primary reviewer and the secondary reviewers was $>85 \%$ for each recommendation. We reconciled differences through a collective discussion of the wording of the regulation until all reviewers were in agreement. To be counted, regulations needed to include clear and specific language embodying the spirit of the IOM recommendations. We reviewed regulations for all 50 US states, the District of Columbia, Puerto Rico, the US Virgin Islands, Guam, and the Department of Defense. The Department of Defense child care regulations govern facilities in residential areas for US soldiers and their dependents stationed both domestically and overseas. We documented regulations consistent with each of the 4 IOM recommendations for healthy sleep practices in child care. We also recorded the date of the most recent revision or update to evaluate if the regulation was adopted before or after the release of the IOM recommendations.

We reviewed regulations for both child care centers ("centers") and family child care homes ("homes"). Generally, centers care for a greater number of children, have 3 or more staff members, and are located in a dedicated building. Homes, on the other hand, typically care for fewer children and include a single care provider who is often the homeowner. Some states regulate subcategories of centers and homes, such as infant care centers or large family child care homes. Where appropriate, we grouped these types of facilities into either "centers" or "homes" for the purpose of reporting results of this review. For example, we classified infant care centers as centers and large family child care homes as homes.

\section{Analysis}

We computed means, frequencies, and SD for the number of regulations for each state according to type of facility. We also categorized states (not including the District of Columbia, the Department of Defense, or the US territories) by geographic census region: Northeast, South, Midwest, and West. We used Cochran-Mantel-Haenszel trend tests to compute correlations between the geographic region of the state and the number of regulations consistent with $10 \mathrm{M}$ recommendations, treated as an ordinal variable ranging from 0 to 4 regulations. Next, we used Cochran-Mantel-Haenszel trend tests to explore associations between the dichotomized year variable (before the release of the $10 \mathrm{M}$ recommendations versus after the release) and number of regulations in each state. Additionally, we computed Spearman correlation coefficients to examine year of last update, treated as a continuous variable, and the number of regulations in each state. We conducted all analyses by using SAS 9.2 (SAS Institute, Inc, Cary, NC), with a significance level of $\alpha=0.05$.

\section{RESULTS}

\section{Overview}

Overall, few states had regulations related to healthy sleep, beyond those aimed at preventing SIDS (Table 1). The mean (SD) number of regulations for states was 0.9 (0.7) for centers and 0.8 (0.7) for homes. No state had regu- lations for all 4, or even 3 of the sleep recommendations for centers or homes. For centers, Arizona, California, Illinois, Massachusetts, Michigan, New Mexico, Oregon, Tennessee, Texas, Utah, and Vermont had regulations for 2 of the 4 recommendations. For homes, Massachusetts, New Mexico, North Dakota, Oregon, Texas, Utah, Vermont, Virginia, and West Virginia had regulations for 2 of the 4 recommendations. Thirty-three states had regulations for centers and 31 had regulations for homes consistent with the recommendation to encourage practices that promote sleep selfregulation. The second most common regulation was related to creating environments that ensure restful sleep. Fifteen states had center regulations and 11 had home regulations consistent with that recommendation. Virginia was the only state with a regulation encouraging sleep-promoting behaviors (homes only) and no states had a regulation requiring consultation from a sleep expert.

When we examined geographic differences, we found that states in the Northeast had the greatest mean (SD) number of regulations, which was $1.2(0.4)$ for centers and 1.1 (0.6) for homes. This is in contract to the South, which had the fewest mean (SD) number of regulations: centers 0.7 (0.7) and homes 0.8 (0.8). The association between geographic region and number of regulations was significant for centers ( $P=.03)$, but not for homes $(P=.14)$. Nineteen states for centers and homes had updated their regulations in 2012 or 2013, after the IOM recommendations were released (Table 2). The year of last update examined as a dichotomized variable (before the recommendations were released versus after) was not associated with the number of regulations consistent with $10 \mathrm{M}$ recommendations for centers $(P=.71)$, but was for homes $(P=.03)$. Similarly, the number of regulations as not correlated with the year of last update examined as a continuous variable for centers (Spearman's 
TABLE 1 State Regulations for Child Care Centers and Family Child Care Homes Consistent With Institute of Medicine Sleep Recommendations

\begin{tabular}{|c|c|c|c|c|c|c|}
\hline State & Facility Type & Year of Last Update & $\begin{array}{c}\text { Create Environments } \\
\text { That Ensure } \\
\text { Restful Sleep }\end{array}$ & $\begin{array}{l}\text { Encourage } \\
\text { Sleep-Promoting } \\
\text { Behaviors }\end{array}$ & $\begin{array}{l}\text { Encourage Practices } \\
\text { That Promote Sleep } \\
\text { Self-Regulation }\end{array}$ & $\begin{array}{l}\text { Seek Consultation } \\
\text { Yearly From } \\
\text { Sleep Expert }\end{array}$ \\
\hline \multirow[t]{2}{*}{$\mathrm{AL}$} & Centers & 2007 & - & - & $x$ & - \\
\hline & Homes & 2007 & - & - & - & - \\
\hline \multirow[t]{2}{*}{ AK } & Centers & 2007 & - & - & - & - \\
\hline & Homes & 2007 & - & - & - & - \\
\hline \multirow[t]{2}{*}{$\mathrm{AZ}$} & Centers & 2010 & $x$ & - & $x$ & - \\
\hline & Homes & 2011 & - & - & $x$ & - \\
\hline \multirow[t]{2}{*}{ AR } & Centers & 2011 & - & - & - & - \\
\hline & Homes & 2011 & - & - & - & - \\
\hline \multirow[t]{2}{*}{ CA } & Centers & 2008 & $x$ & - & $x$ & - \\
\hline & Homes & 2009 & - & - & - & - \\
\hline \multirow[t]{2}{*}{$\mathrm{CO}$} & Centers & 2012 & - & - & $x$ & - \\
\hline & Homes & 2012 & - & - & $x$ & - \\
\hline \multirow[t]{2}{*}{ CT } & Centers & 2013 & - & - & $x$ & - \\
\hline & Homes & 2013 & - & - & - & - \\
\hline \multirow[t]{2}{*}{$\mathrm{DE}$} & Centers & 2007 & - & - & $x$ & - \\
\hline & Homes & 2009 & - & - & - & - \\
\hline \multirow[t]{2}{*}{$\mathrm{FL}$} & Centers & 2010 & - & - & - & - \\
\hline & Homes & 2010 & - & - & - & - \\
\hline \multirow[t]{2}{*}{ GA } & Centers & 2013 & $x$ & - & - & - \\
\hline & Homes & 2012 & $x$ & - & - & - \\
\hline \multirow[t]{2}{*}{$\mathrm{HI}$} & Centers & 2002 & $x$ & - & - & - \\
\hline & Homes & 2002 & - & - & - & - \\
\hline \multirow[t]{2}{*}{ ID } & Centers & 2011 & - & - & - & - \\
\hline & Homes & 2011 & - & - & - & - \\
\hline \multirow[t]{2}{*}{ IL } & Centers & 2010 & $x$ & - & $x$ & - \\
\hline & Homes & 2010 & - & - & $x$ & - \\
\hline \multirow[t]{2}{*}{ IN } & Centers & 2003 & - & - & $x$ & - \\
\hline & Homes & 2001 & - & - & $x$ & - \\
\hline \multirow[t]{2}{*}{ IA } & Centers & 2012 & - & - & - & - \\
\hline & Homes & 2012 & - & - & - & - \\
\hline KS & Centers & 2012 & - & - & $x$ & - \\
\hline & Homes & 2012 & - & - & $x$ & - \\
\hline KY & Centers & 2008 & - & - & - & - \\
\hline & Homes & 2008 & - & - & - & - \\
\hline LA & Centers & 2012 & - & - & - & - \\
\hline & Homes & - & - & - & - & - \\
\hline ME & Centers & 2008 & - & - & $x$ & - \\
\hline & Homes & 2009 & - & - & $x$ & - \\
\hline MD & Centers & 2012 & - & - & - & - \\
\hline & Homes & 2012 & - & - & $x$ & - \\
\hline MA & Centers & 2010 & $x$ & - & $x$ & - \\
\hline & Homes & 2010 & $x$ & - & $x$ & - \\
\hline $\mathrm{Ml}$ & Centers & 2008 & $x$ & - & $x$ & - \\
\hline & Homes & 2009 & - & - & - & - \\
\hline MN & Centers & 2010 & $x$ & - & - & - \\
\hline & Homes & 2007 & - & - & - & - \\
\hline MS & Centers & 2009 & - & - & - & - \\
\hline & Homes & 2009 & - & - & - & - \\
\hline MO & Centers & 2011 & - & - & $x$ & - \\
\hline & Homes & 2011 & - & - & $x$ & - \\
\hline MT & Centers & 2012 & - & - & $x$ & - \\
\hline & Homes & 2012 & - & - & $x$ & - \\
\hline NE & Centers & 2013 & - & - & - & - \\
\hline & Homes & 2013 & - & - & - & - \\
\hline NV & Centers & 2012 & - & - & $x$ & - \\
\hline & Homes & 2012 & - & - & $x$ & - \\
\hline $\mathrm{NH}$ & Centers & 2008 & - & - & $x$ & - \\
\hline & Homes & 2008 & - & - & $x$ & - \\
\hline NJ & Centers & 2009 & - & - & $x$ & - \\
\hline & Homes & 2009 & - & - & $x$ & - \\
\hline
\end{tabular}


TABLE 1 Continued

\begin{tabular}{|c|c|c|c|c|c|c|}
\hline State & Facility Type & Year of Last Update & $\begin{array}{l}\text { Create Environments } \\
\text { That Ensure } \\
\text { Restful Sleep }\end{array}$ & $\begin{array}{c}\text { Encourage } \\
\text { Sleep-Promoting } \\
\text { Behaviors }\end{array}$ & $\begin{array}{c}\text { Encourage Practices } \\
\text { That Promote Sleep } \\
\text { Self-Regulation }\end{array}$ & $\begin{array}{l}\text { Seek Consultation } \\
\text { Yearly From } \\
\text { Sleep Expert }\end{array}$ \\
\hline \multirow[t]{2}{*}{ NM } & Centers & 2012 & $x$ & - & $x$ & - \\
\hline & Homes & 2012 & X & - & X & - \\
\hline \multirow[t]{2}{*}{ NY } & Centers & 2005 & - & - & $x$ & - \\
\hline & Homes & 2005 & - & - & $x$ & - \\
\hline \multirow[t]{2}{*}{ NC } & Centers & 2013 & - & - & $x$ & - \\
\hline & Homes & 2013 & - & - & $x$ & - \\
\hline \multirow[t]{2}{*}{ ND } & Centers & 2013 & - & - & $x$ & - \\
\hline & Homes & 2013 & $x$ & - & $x$ & - \\
\hline \multirow[t]{2}{*}{$\mathrm{OH}$} & Centers & 2010 & - & - & $x$ & - \\
\hline & Homes & 2011 & - & - & $x$ & - \\
\hline \multirow[t]{2}{*}{ OK } & Centers & 2010 & - & - & $x$ & - \\
\hline & Homes & 2010 & - & - & - & - \\
\hline \multirow[t]{2}{*}{ OR } & Centers & 2011 & $x$ & - & $x$ & - \\
\hline & Homes & 2011 & $x$ & - & $x$ & - \\
\hline \multirow[t]{2}{*}{ PA } & Centers & 2009 & $x$ & - & - & - \\
\hline & Homes & 2009 & $x$ & - & - & - \\
\hline \multirow[t]{2}{*}{$\mathrm{RI}$} & Centers & 1993 & - & - & $x$ & - \\
\hline & Homes & 2007 & - & - & $x$ & - \\
\hline \multirow[t]{2}{*}{ SC } & Centers & 2005 & - & - & $x$ & - \\
\hline & Homes & 2005 & - & - & $x$ & - \\
\hline \multirow[t]{2}{*}{ SD } & Centers & 2013 & - & - & - & - \\
\hline & Homes & 2013 & - & - & - & - \\
\hline \multirow[t]{2}{*}{ TN } & Centers & 2009 & $x$ & - & $x$ & - \\
\hline & Homes & 2009 & - & - & $x$ & - \\
\hline \multirow[t]{2}{*}{ TX } & Centers & 2013 & $x$ & - & $x$ & - \\
\hline & Homes & 2013 & $x$ & - & $x$ & - \\
\hline \multirow[t]{2}{*}{ UT } & Centers & 2013 & $x$ & - & $x$ & - \\
\hline & Homes & 2013 & $x$ & - & $x$ & - \\
\hline \multirow[t]{2}{*}{ VT } & Centers & 2001 & $x$ & - & $x$ & - \\
\hline & Homes & 2001 & $x$ & - & $x$ & - \\
\hline \multirow[t]{2}{*}{ VA } & Centers & 2012 & - & - & $x$ & - \\
\hline & Homes & 2013 & $x$ & $x$ & - & - \\
\hline \multirow[t]{2}{*}{ WA } & Centers & 2013 & - & - & $x$ & - \\
\hline & Homes & 2013 & - & - & $x$ & - \\
\hline \multirow[t]{2}{*}{ WV } & Centers & 2009 & - & - & $x$ & - \\
\hline & Homes & 2012 & $x$ & - & $x$ & - \\
\hline \multirow[t]{2}{*}{ WI } & Centers & 2009 & - & - & $x$ & - \\
\hline & Homes & 2009 & - & - & $x$ & - \\
\hline \multirow[t]{2}{*}{ WY } & Centers & 2013 & - & - & - & - \\
\hline & Homes & 2013 & - & - & - & - \\
\hline DC & Centers & 2007 & - & - & - & - \\
\hline & Homes & 2007 & - & - & - & - \\
\hline PR & Centers & 1992 & - & - & - & - \\
\hline & Homes & 1992 & - & - & - & - \\
\hline USVI & Centers & 2011 & - & - & - & - \\
\hline & Homes & 2011 & - & - & - & - \\
\hline GU & Centers & 1997 & - & - & - & - \\
\hline & Homes & 1997 & - & - & - & - \\
\hline DOD & Centers & 1996 & - & - & - & - \\
\hline & Homes & 1996 & - & - & - & - \\
\hline
\end{tabular}

DOD, Department of Defense; GU, Guam; PR, Puerto Rico; USVI, United States Virgin Islands; -, indicates the absence of a regulation.

$\rho=0.02 ; P=.88$ ), but was positively correlated for homes (Spearman's $\rho=$ 0.30; $P=.03$ ).

\section{DISCUSSION}

In this review of state regulations targeting healthy sleep practices, we found that states had few regulations consistent with IOM recommendations. No state had regulations for all 4 recommendations for centers or homes, and most states had only 1 or 2 regulations consistent with the 4 recommendations. When we examined geographic variation, we found differences by census region for centers but not homes. States in the Northeast had the greatest number of regulations for centers, and states in the South had the fewest. It may be that centers are more tightly regulated by states and have more 
TABLE 2 State Regulations for Child Care Centers and Family Child Care Homes Updated in 2012 or 2013 and Consistent With Institute of Medicine Sleep Recommendations

\begin{tabular}{lll}
\hline Number of Regulations & \multicolumn{1}{c}{ States With Center Regulations } & States With Home Regulations \\
\hline 0 & IA, LS, MD, NE, SD, WY & CT, IA, NE, SD, WY \\
1 & CO, CT, GA, KS, MT, NV, NC, ND, VA, WA & CO, GA, KS, MD, MT, NV, NC, WA \\
2 & NM, TX, UT & NM, ND, TX, UT, VA, WV \\
\hline
\end{tabular}

regulations in general, compared with homes. Therefore, they may be more likely to cluster by geographic region, with center regulations more similar among neighboring states. In our previous study examining state child care regulations related to healthy infant feeding practices, we did not observe geographic differences in the number of state regulations for centers or homes. ${ }^{37}$ Additionally, the number of state regulations was not correlated with the year of last update, but in that study we were not comparing regulations to recently released recommendations. ${ }^{37}$ In the current study, we found that states that had updated their regulations after the IOM recommendations were released had more regulations consistent with the recommendations for homes, but not for centers. This suggests that the $10 \mathrm{M}$ recommendations may have prompted new regulations, although we were not able to assess the extent to which the IOM report influenced policy decisions within states and therefore cannot draw any firm conclusions.

We also found that no state had a regulation consistent with the recommendation to seek consultation yearly from a sleep expert, except in the context of SIDS prevention. Although consultation may be beneficial, the logistical limitations associated with the implementation of this recommendation raise concerns. If states were to mandate consultation on healthy sleep durations and practices, it would certainly increase the need for sleep experts. But without additional resources and further training of health professionals, this need may largely go unmet.
There are other important factors to consider related to sleep and obesity. First, although the majority of child care takes place during the day, 30,31 much of the research examining sleep and obesity combined daytime and nighttime sleep to compute total duration. A few studies considered nighttime sleep exclusively and found an increased risk for obesity or obesity-related behaviors, 20,38 and some have reported that daytime sleep had little influence on the relationship between nighttime sleep and obesity. ${ }^{20,21,39}$ However, 1 previous study found that daytime naps helped protect against obesity. ${ }^{40}$ There is some evidence that daytime naps do not substitute for nighttime sleep in the prevention of obesity, ${ }^{20}$ and that children who nap during child care may sleep fewer hours at night. ${ }^{41}$ This may be especially important for parents whose children sleep for long durations during the day in child care. Future studies should explore the extent to which daytime naps contribute to the prevention of obesity when considering total daily sleep duration, as this information will have important implications for recommendations related to sleep in child care.

Second, although a number of studies found a relationship between sleep and obesity, researchers defined short sleep duration differently. In fact, 2 recent systematic reviews examined sleep duration and weight gain, and neither explored differences in researcher definitions of insufficient sleep. Without a widely accepted definition of short sleep duration, it is challenging to fully evaluate the relationship between sleep and obesity in children. This lack of consistency has prompted recent calls for additional research in this area, especially for studies identifying ideal sleep durations in childhood. ${ }^{34,42}$ As a result, some researchers have explored sleep duration norms in children and provide reference data to inform guidelines. ${ }^{43,44}$ Recent recommendations put forth by the $\mathrm{Na}$ tional Sleep Foundation provide additional guidance on appropriate sleep durations for young children. ${ }^{45}$ However, these durations are not specifically linked to the prevention of obesity, and individual needs may vary. These guidelines range from 10.5 to 18 hours of sleep within a 24-hour period for infants, to 11 to 13 hours within a 24-hour period for preschoolers. ${ }^{45}$ The $10 \mathrm{M}$ recommendations encourage adherence to these sleep duration guidelines, but future research should evaluate whether these durations are protective against obesity.

Finally, it is important to recognize that daytime sleep in child care may be a point of contention between parents and providers. If providers encourage longer naps during the day, these may, in turn, influence children's nighttime sleep duration. Previous studies have found that child care attendance was associated with shorter nighttime sleep duration for infants, ${ }^{24}$ and that daytime sleep in child care decreased nighttime sleep at home for preschoolers. ${ }^{41}$ Future sleep recommendations targeting child care settings should consider the relationship between parents and providers, as well as the extent to which daytime naps affect nighttime sleep duration.

Although previous studies have compared state regulations to national standards, including those related to obesity ${ }^{46}$ and SIDS prevention, ${ }^{47,48}$ this current review is the first to consider sleep regulations as a means of preventing obesity in young children. The previous study examining regulations related to obesity prevention focused on dietary and physical activity behaviors in child care. When comparing our review results to that previous review, 
Tennessee was the only state among those with the highest number of regulations for centers in both studies. For homes, states with the highest number of regulations in both reviews were Oregon, Texas, Vermont, and West Virginia. Previous studies have examined sleep regulations to help prevent SIDS before and after the Back to Sleep campaign (now Safe to Sleep), ${ }^{49}$ but these reviews were conducted in 2000 and 2005, making comparisons less meaningful; the majority of states have since updated their regulations. ${ }^{47,48}$ Future studies could explore the extent to which states had both regulations promoting healthy sleep practices for obesity prevention and regulations that encouraged behaviors to help prevent SIDS.

Despite the usefulness of regulatory reviews, at any given time a number of states are in the process of making changes to their regulations. Thus, this

\section{REFERENCES}

1. Beebe DW. Cognitive, behavioral, and functional consequences of inadequate sleep in children and adolescents. Pediatr Clin North Am. 2011;58(3):649-665

2. Kelly $Y$, Kelly J, Sacker A. Changes in bedtime schedules and behavioral difficulties in 7 year old children. Pediatrics. 2013;132 (5). Available at: www.pediatrics.org/cgi/ content/full/132/5/e1184

3. Paavonen EJ, Porkka-Heiskanen T, Lahikainen AR. Sleep quality, duration and behavioral symptoms among 5-6-year-old children. Eur Child Adolesc Psychiatry. 2009;18(12):747754

4. Magee L, Hale L. Longitudinal associations between sleep duration and subsequent weight gain: a systematic review. Sleep Med Rev. 2012;16(3):231-241

5. Patel SR, Hu FB. Short sleep duration and weight gain: a systematic review. Obesity (Silver Spring). 2008;16(3):643-653

6. Chen X, Beydoun MA, Wang Y. Is sleep duration associated with childhood obesity? $A$ systematic review and meta-analysis. Obesity (Silver Spring). 2008;16(2):265-274

7. Spiegel K, Tasali E, Penev P, Van Cauter E. Brief communication: Sleep curtailment in healthy young men is associated with de- review is current as of 2013. However, results provide important information about regulations at the time of the review, and could serve as a baseline to assess future regulatory changes. Additionally, although regulations are compulsory, they do not necessarily indicate actual practice. Future studies should assess the extent to which actual practices, such as sleep-promoting behaviors in child care, are consistent with state regulations.

\section{CONCLUSIONS}

Evidence on the importance of sleep for obesity prevention continues to accumulate. Insufficient sleep durations in early childhood have been linked to obesity in later childhood and adolescence, ${ }^{18,23,40,50,51}$ emphasizing the need for early intervention. Because the majority of young children spend time in child care outside of the home, these facilities have become targets for

creased leptin levels, elevated ghrelin levels, and increased hunger and appetite. Ann Intern Med. 2004;141(11):846-850

8. Taheri S, Lin L, Austin D, Young T, Mignot E. Short sleep duration is associated with reduced leptin, elevated ghrelin, and increased body mass index. PLoS Med. 2004;1 (3): e62

9. Knutson KL, Spiegel K, Penev P, Van Cauter $E$. The metabolic consequences of sleep deprivation. Sleep Med Rev. 2007;11(3): 163-178

10. Chaput J-P, Després JP, Bouchard C, Astrup A, Tremblay A. Sleep duration as a risk factor for the development of type 2 diabetes or impaired glucose tolerance: analyses of the Quebec Family Study. Sleep Med. 2009;10 (8):919-924

11. Crespo CJ, Smit E, Troiano RP, Bartlett SJ, Macera CA, Andersen RE. Television watching, energy intake, and obesity in US children: results from the third National Health and Nutrition Examination Survey, 19881994. Arch Pediatr Adolesc Med. 2001;155 (3):360-365

12. Tatone-Tokuda F, Dubois L, Ramsay $T$, et al. Sex differences in the association between sleep duration, diet and body mass index: obesity prevention. ${ }^{32,33}$ In this review, few states had regulations related to healthy sleep practices consistent with the $10 \mathrm{M}$ recommendations. Results suggest that states that had updated their regulations after the IOM report was released had more regulations consistent with the recommendations. The report provides an important first step toward increasing awareness of sleep practices in child care. However, as new research emerges, these policy-based recommendations should be refined to reflect best practices. As recommendations evolve, it will be important to assess the extent to which states revise their regulations to be consistent with new recommendations. Additionally, public health and early childhood professionals should assist states with the adoption of regulations consistent with evidence-based recommendations for healthy sleep practices in child care. a birth cohort study. J Sleep Res. 2012;21 (4):448-460

13. Must A, Parisi SM. Sedentary behavior and sleep: paradoxical effects in association with childhood obesity. Int J Obes (Lond). 2009;33(suppl 1):S82-S86

14. Benedict C, Hallschmid M, Lassen A, et al. Acute sleep deprivation reduces energy expenditure in healthy men. Am J Clin Nutr. 2011;93(6):1229-1236

15. Ortega FB, Ruiz JR, Labayen I, et al. Sleep duration and activity levels in Estonian and Swedish children and adolescents. Eur J Appl Physiol. 2011;111(10):2615-2623

16. Wennman $\mathrm{H}$, Kronholm E, Partonen $\mathrm{T}$, et al. Physical activity and sleep profiles in Finnish men and women. BMC Public Health 2014;14(1):82

17. Sekine $M$, Yamagami $T$, Handa $K$, et al. A dose-response relationship between short sleeping hours and childhood obesity: results of the Toyama Birth Cohort Study. Child Care Health Dev. 2002;28(2):163-170

18. Reilly JJ, Armstrong J, Dorosty AR, et al; Avon Longitudinal Study of Parents and Children Study Team. Early life risk factors for obesity in childhood: cohort study. $B M J$. 2005;330(7504):1357 
19. Taveras EM, Rifas-Shiman SL, Oken E, Gunderson EP, Gillman MW. Short sleep duration in infancy and risk of childhood overweight. Arch Pediatr Adolesc Med. 2008;162(4):305-311

20. Bell JF, Zimmerman FJ. Shortened nighttime sleep duration in early life and subsequent childhood obesity. Arch Pediatr Adolesc Med. 2010;164(9):840-845

21. Jiang F, Zhu S, Yan C, Jin X, Bandla H, Shen $X$. Sleep and obesity in preschool children. J Pediatr. 2009;154(6):814-818

22. Tikotzky L, DE Marcas G, Har-Toov J, Dollberg S, Bar-Haim Y, Sadeh A. Sleep and physical growth in infants during the first 6 months. J Sleep Res. 2010;19(1 pt 1):103-110

23. Snell EK, Adam EK, Duncan GJ. Sleep and the body mass index and overweight status of children and adolescents. Child Dev. 2007;78(1):309-323

24. Nevarez MD, Rifas-Shiman SL, Kleinman KP, Gillman MW, Taveras EM. Associations of early life risk factors with infant sleep duration. Acad Pediatr. 2010;10(3):187-193

25. Cespedes EM, Gillman MW, Kleinman K, Rifas-Shiman SL, Redline S, Taveras EM. Television viewing, bedroom television, and sleep duration from infancy to mid-childhood. Pediatrics. 2014; [Epub ahead of print]

26. Marinelli M, Sunyer J, Alvarez-Pedrerol M, et al. Hours of television viewing and sleep duration in children: a multicenter birth cohort study. JAMA Pediatr. 2014;168(5): 458-464

27. Magee CA, Lee JK, Vella SA. Bidirectional relationships between sleep duration and screen time in early childhood. JAMA Pediatr. 2014;168(5):465-470

28. Mindell JA, Meltzer LJ, Carskadon MA, Chervin RD. Developmental aspects of sleep hygiene: findings from the 2004 National Sleep Foundation sleep in America poll. Sleep Med. 2009;10(7):771-779

29. Wilson KE, Miller AL, Lumeng JC, Chervin $\mathrm{RD}$. Sleep environments and sleep durations in a sample of low-income preschool children. J Clin Sleep Med. 2014;10(3):299305
30. United States Census Bureau. Who's minding the kids? Child care arrangements: spring 2011 Available at: www.census.gov/prod/ 2013pubs/p70-135.pdf. Accessed January 26, 2014

31. Federal Interagency Forum on Child and Family Statistics. America's Children: Key National Indicators of Well-Being, 2013. Washington, DC: US Government Printing Office; 2013

32. Story M, Kaphingst KM, French $\mathrm{S}$. The role of child care settings in obesity prevention. Future Child. 2006;16(1):143-168

33. Larson N, Ward DS, Neelon SB, Story M. What role can child-care settings play in obesity prevention? A review of the evidence and call for research efforts. $J$ Am Diet Assoc. 2011;111(9):1343-1362

34. Institute of Medicine. Early Childhood Obesity Prevention Policies. Washington, DC: The National Academies Press; 2011

35. National Resource Center for Health and Safety in Child Care and Early Education. Available at: http://nrckids.org/default/index. cfm/regulators/. Accessed February 19, 2014

36. Mersky RM, Dunn DJ. Fundamentals of Legal Research, 8th ed. New York, NY: Foundation Press; 2002

37. Benjamin SE, Taveras EM, Cradock AL, Walker EM, Slining MM, Gillman MW. State and regional variation in regulations related to feeding infants in child care. Pediatrics. 2009;124(1). Available at: www. pediatrics.org/cgi/content/full/124/1/e104

38. Kjeldsen JS, Hjorth MF, Andersen R, et al. Short sleep duration and large variability in sleep duration are independently associated with dietary risk factors for obesity in Danish school children. Int $J$ Obes (Lond). 2014;38(1):32-39

39. Miller AL, Kaciroti N, Lebourgeois MK, Chen YP, Sturza J, Lumeng JC. Sleep timing moderates the concurrent sleep duration-body mass index association in low-income preschool-age children. Acad Pediatr. 2014;14(2):207-213

40. Agras WS, Hammer LD, McNicholas F, Kraemer HC. Risk factors for childhood overweight: a prospective study from birth to 9.5 years. J Pediatr. 2004;145(1):20-25
41. Ward TM, Gay C, Anders TF, Alkon A, Lee KA. Sleep and napping patterns in 3-to-5-year old children attending full-day childcare centers. J Pediatr Psychol. 2008;33(6):666672

42. Lumeng JC. Future directions for research on sleep durations in pediatric populations. Sleep. 2010;33(10):1281-1282

43. Williams JA, Zimmerman FJ, Bell JF. Norms and trends of sleep time among US children and adolescents. JAMA Pediatr. 2013; 167(1):55-60

44. Galland BC, Taylor BJ, Elder DE, Herbison P. Normal sleep patterns in infants and children: a systematic review of observational studies. Sleep Med Rev. 2012;16(3):213-222

45. National Sleep Foundation. Children and sleep. Available at: http://sleepfoundation.org/ sleep-topics/children-and-sleep. Accessed July 16, 2014

46. Benjamin SE, Cradock A, Walker EM, Slining M, Gillman MW. Obesity prevention in child care: a review of U.S. state regulations. BMC Public Health. 2008;8(8):188

47. Moon RY, Biliter WM, Croskell SE. Examination of state regulations regarding infants and sleep in licensed child care centers and family child care settings. Pediatrics. 2001;107 (5):1029-1036

48. Moon RY, Kotch L, Aird L. State child care regulations regarding infant sleep environment since the Healthy Child Care America-Back to Sleep campaign. Pediatrics. 2006;118(1):73-83

49. United States Department of Health and Human Services. Safe to sleep public education campaign. Available at: www.nichd. nih.gov/sts/campaign/Pages/default.aspx. Accessed January 29, 2014

50. Lumeng JC, Somashekar D, Appugliese D, Kaciroti N, Corwyn RF, Bradley RH. Shorter sleep duration is associated with increased risk for being overweight at ages 9 to 12 years. Pediatrics. 2007;120(5): 1020-1029

51. Taveras EM, Gillman MW, Peña MM, Redline S, Rifas-Shiman SL. Chronic sleep curtailment and adiposity. Pediatrics. 2014;133(6):10131022 